\title{
WEBSITE REVIEW \\ www.eds.org
}

*Mrs. Pratibha P

www.edx.org is a platform which offers 1,900 + online courses in various subjects such as humanities, mathematics, computer science and management from the world's best universities and institutions. This portal helps in educating the people by offering courses anytime anywhere. They presently have 14 Million + learners worldwide, representing every country. EdX offers the highest quality courses from institutions who share their commitment to excellence in teaching and learning. They also have 52 Million + enrollments across edX courses.

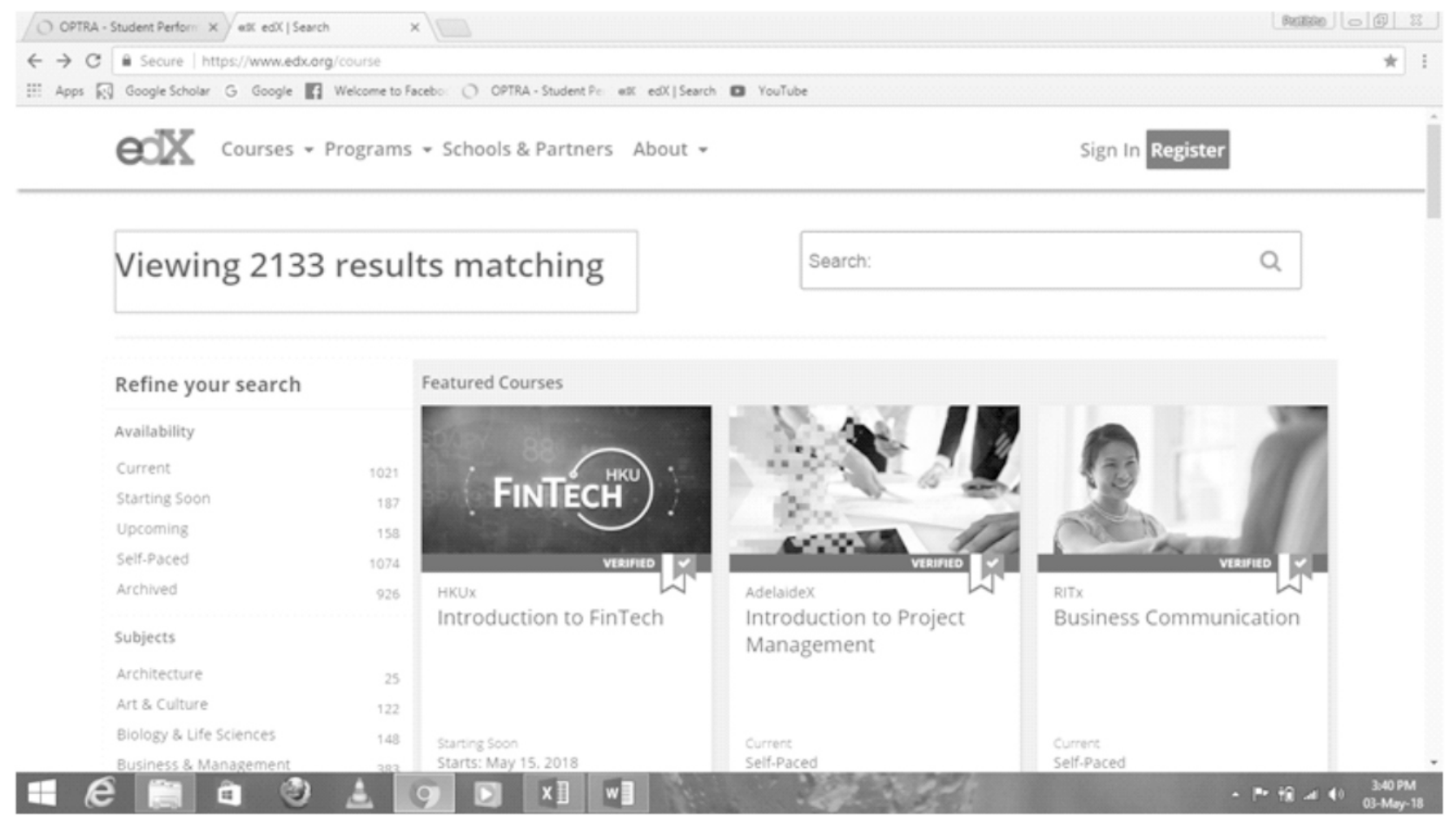

EdX was founded by Harvard University and The mission of edX includes:

MIT in May 2012 and currently having 130 Global partners. The edX platform facilitates feedback from the learners and provides quick response. The CEO of edX is Mr. Ananth Agarwal.

- Increase access to higher quality education for everyone, everywhere

- $\quad$ Enhance teaching and learning on campus and online

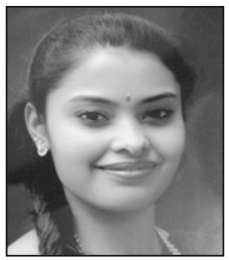

*Mrs. Pratibha $\mathbf{P}$

Assistant Professor

Adarsh Institute of Management and

Information Technology

Bangalore 
- Advance learning and teaching through research

The courses offered are in large used to teach and learn along with the curriculum. The concept of blending MOOC with the classroom teaching will have a greater impact on the understanding of the subject. Another advantage of edX platform is that it provides free as well as paid courses. The learner can choose an audited course (Free version) or the certified course (Paid version). Because edX is a non-profit organization, the funds generated from verified students are used for creating and improving the future classes. edX is available in English, French, Hindi, Mandarin and Spanish.

They have 3 programs:

Micro Masters Certificate: A series of Master's-level courses which helps in advancing a career. It is created by top universities and recognized by companies. Micro Masters Programs are credit-eligible, provide in-demand knowledge and may be applied to accelerate a Master's Degree.

Professional Certificate: It is a program designed by industry leaders and top universities to enhance professional skills. Professional Certificates develop the proficiency and expertise that employers are looking for with specialized training and professional education.

$X$ series program: It is created by worldrenowned experts and top universities, XSeries are designed to provide a deep understanding of key subjects through a series of courses. Once complete, the learner will earn a valuable XSeries Certificate that illustrates his/her achievement.
In the dashboard, the courses enrolled for will be evidently be visible. The course platform has the following tabs:

1. Course: This tab indicates the blue print of the course. The number of units or modules in the course with their sub-topics can be viewed here.

2. Syllabus: This tab indicated the course description with the introduction to the instructor. The prerequisites, outcomes, basis for grading and certification, workload and schedule are mentioned here. To facilitate navigation within each unit, the course materials and activities are organized under the following headings:

a) About this video: Precedes each video lesson and provides a summary of the topics covered.

b) Discussion: Gives each student a chance to join discussions about course topic and question prompts. This is ungraded but highly recommended.

c) Surveys and self-assessments: Anonymous polls and surveys. These often include a related discussion prompt.

d) Word cloud: An activity where an image composed of words used in a particular text or subject, in which the size of each word indicates its frequency or importance.

e) Check your understanding (Ungraded quiz or self- assessment): Contains ungraded knowledge check questions or self-assessment activities. These may come before or after video lessons. They help the learner determine his/her current level of understanding about course topics. 
f) Deep dive: External websites that contain related readings or resources. These links will open in a new window.

g) Quiz: Graded quizzes at the end of each unit. These are required for verified students to obtain the certificate of completion.

3. Schedule: It involves the weekly outline chart and also comprises the key course dates i.e. the last date by which the course needs to be completed and the last date for up gradation.

4. FAQ: This contains the questions frequently asked by the students. If a question rises in the students and not present in this tab, they can mail the support team for the answers.

5. Discussion: The student can add a post, search for posts in the course topics or as well be a part of the general discussion forum.

6. Progress: Here the progress of the students in relation to the course is clearly shown. Detailed analysis of the answers is also presented.

Some of the universities which are a part of the edX platform are Harvard University, Berkley University of California, Rochester Institute of Technology, Massachusetts Institute of Technology, Microsoft, Delft University of Technology, Columbia University, University of Pennsylvania, The University of Queensland, Indian Institute of Management, Bangalore and many more.

The platform is designed in a way that the navigation over the course progress is quite simple and easily understandable. Once logged in, the courses enrolled for can easily be seen and resumed as show below:

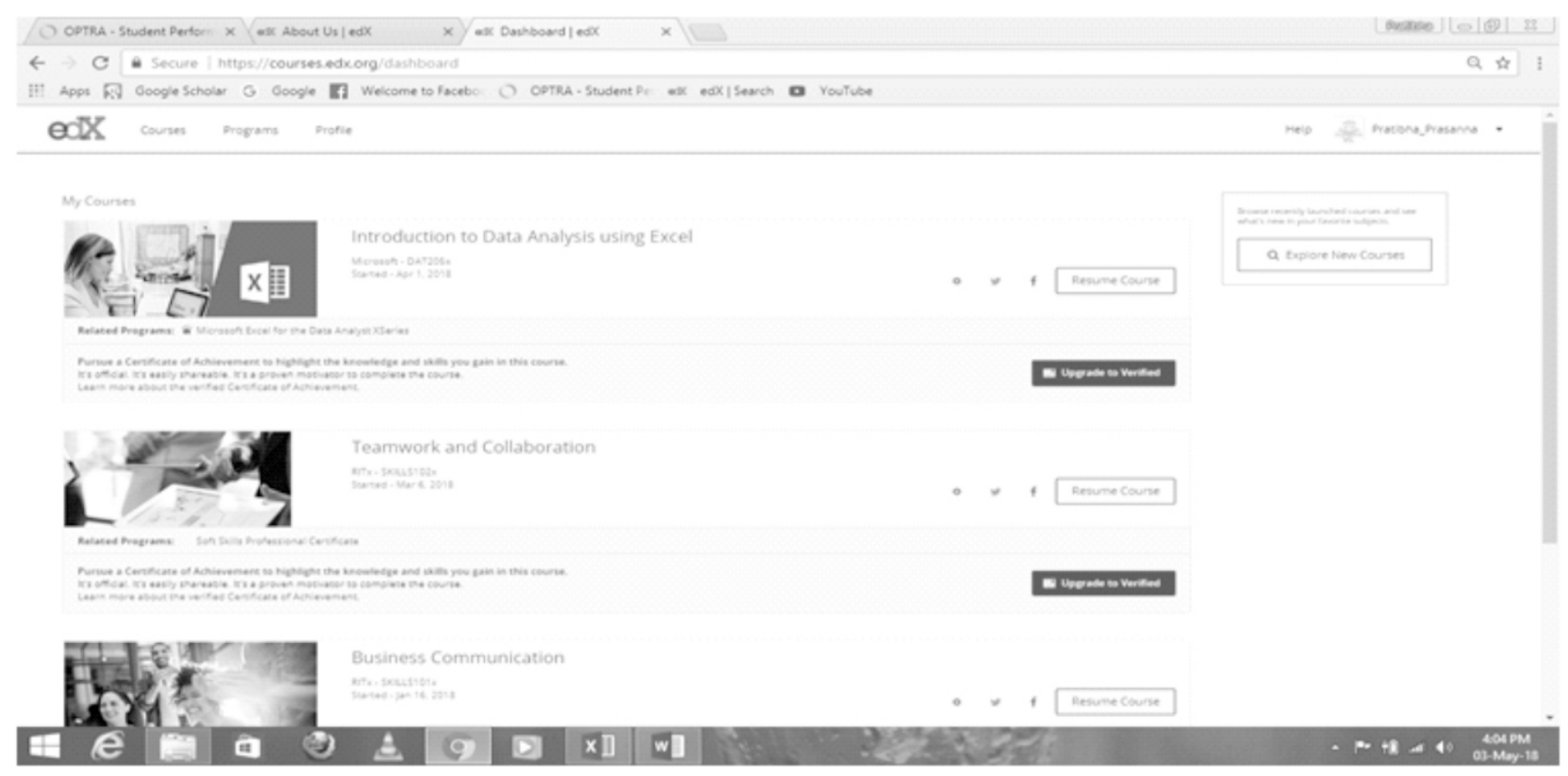




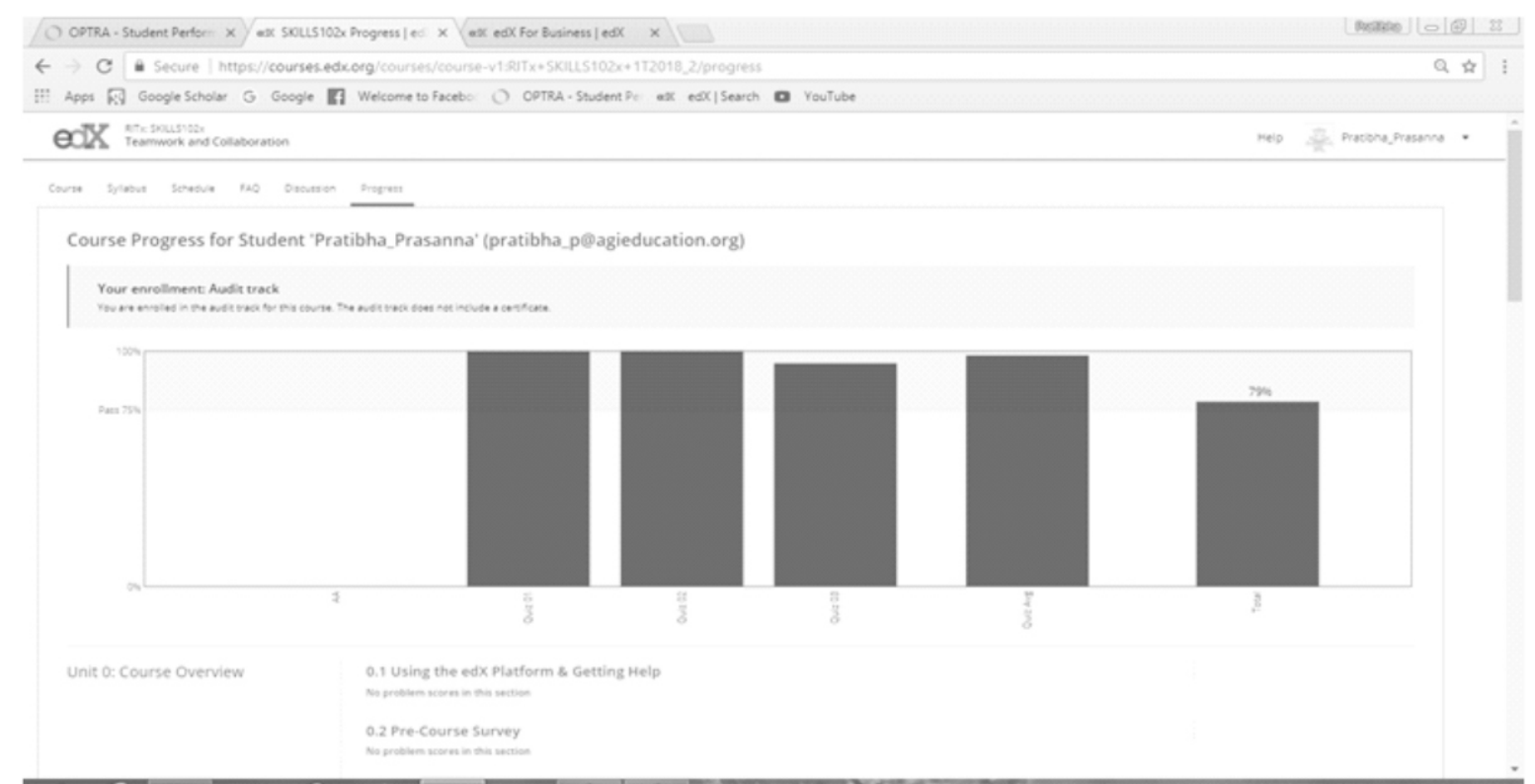

The following are the positive observations from the website:

- The site is user friendly and responsive.

- The images used in the website are very colorful and hence attractive.

- When auditing the course, the learner can have the progress report to support his completion of the course instead of the paid certificate.

- It also has a separate platform to those who want to start a business with edX.

- $\quad$ edX recommends courses based on search history of the user.

- Companies are using the certificates provided by edX as a recruitment tool.

However there are certain improvements which could make this site effective. They are:

- The timing of each course might be ambiguous as it is mentioned in the UTC format.

- The website could be modified so that it could be country centric and easily understandable.

- Certain modules are provided only for the certified students while those auditing the course cannot learn these.
- The courses are time bound and need to be completed within the time frame allotted.

- When the courses are available only for the verified students, audited students sometimes don't have a chance to complete the course and cannot attain the pass percentage.

- Same courses when opted by 2 or more people, the assessment tests can be copied. Hence a software could be developed which would alter the questions for each student.

\section{Conclusion:}

edX is a platform which has made learning an enjoyable journey. It is no more difficult to access good quality education as this is a platform which has made convenient learning possible. Adding to this is that without having to visit a University, one can learn courses conveniently by choosing the time slot when they are available. The courses are offered for all the students irrespective of any prerequisites and thus anyone can join before the course ends. This invitation is like boon as it invites all sorts of students with different requisites. Overall, this platform has made knowledge available at our fingertips. 